\title{
Developing Line Managers as People Managers: HRD Impact in DFPCL, India ${ }^{1}$
}

\author{
Naresh Pinisetti, Deepak Fertilisers and Petrochemicals Corporation \\ Ashutosh Sharma, Deepak Fertilisers and Petrochemicals Corporation \\ Preeti Datta, Deepak Fertilisers and Petrochemicals Corporation
}

\begin{abstract}
Human Resource Development (HRD) within an organizational context continues to face challenges to demonstrate impact and contribution to business success. This article provides an account of HRD practice in a large Indian manufacturing company. A difficult business and industrial relations context in the early 2010s provided the stimulus for HRD to take a more strategic role within the organization. The article focuses upon HRD's initiative with the company's line managers. Fundamentally managers needed to take greater responsibility for managing their people. The approach followed and the interventions made to equip managers with a set of new capabilities are critically assessed. The initiative reflects how, appropriately positioned and supported, HRD's impact can be significant in terms of business performance.
\end{abstract}

Key Words: HRD practice, impact, line managers, development, India

\section{Introduction}

Deepak Fertilisers and Petrochemicals Corporation Ltd is a leading Indian manufacturer of Industrial Chemicals. Set up in 1979 as an ammonia manufacturer, DFPCL today is a publicly listed, multi-product Indian conglomerate with an annual turnover of over half a billion USD. It has a multi-product portfolio spanning industrial chemicals, bulk and specialty fertilizers, farming diagnostics and solutions, technical ammonium nitrate, mining services and consulting and value added real estate. The company is headquartered at Pune. It has a management workforce of a little over 1,000. Its main manufacturing site (one of three) is located at Taloja, with a unionized workforce of approximately 400.

The origins of the particular initiative discussed in this article can be traced back to the latter part of the 2000s and early 2010s, a period characterized by sub-optimal industrial relations together with emergence of restrictive IR practices. It is important to note that prior to 2014 the plant at Taloja, was receiving subsidized natural gas that provided some degree of cost advantage in a highly controlled fertilizer market in India. Over these years, several work practices and behaviours - that negatively affected manufacturing productivity and efficiency - took root within the organization. For example: overmanning; production at any cost; lack of required sense of urgency and a general indiscipline and disengagement of unionized workers towards work. Management found it difficult to take ownership and responsibility for ensuring high standards of performance, including safe working, and the equitable implementation of policies and procedures. Relations generally between managers and workers were less than harmonious. 
In 2012, The Chairman and Managing Director (CMD), shortly after taking the new role, took cognizance of the situation and decided to question the organization's approach to managing people. It was against this background that the company sought a long-term settlement with the union for the period 2012 to 2016, with the major objective of rationalizing manpower and establishing a performance oriented culture at the main manufacturing unit at Taloja. The move was blocked by the union and a strike was declared in January 2013. Some workmen also resorted to misconduct and violent behaviour during the strike. Managers ran the manufacturing unit uninterruptedly during the strike and established new benchmarks for production and productivity. The union relented after five months of strike and agreed to the settlement terms and conditions - including rationalization of manpower, the introduction of a performance management system for workers, and disciplinary action against workers involved in misconduct during strike period.

The early 2010s also saw growing disengagement among the management staff at individual contributor level in other business units. There was a general dissatisfaction with people processes and practices like Performance Management System, Learning Opportunities, Career Development, Rewards and Recognition etc. Managers mistakenly believed that responsibility of people rested with HR department. Hence, they would shy away from the responsibility of setting goals, providing regular feedback, and taking action against non-performance or indiscipline.

\section{A New Approach}

A new head of Group HR, joining the business in 2013, began work towards introducing a more progressive HR and IR strategy in the organization. He worked with his team members to develop and nurture a more collaborative way of working across the organization. To use a well-worn cliché, there was a requirement to "change the rules of the game". Such aspirations assumed considerably greater importance with the withdrawal of subsidized natural gas in 2014. A more engaged and productive workforce was no longer something 'nice to have'; it had become a business necessity.

In an effort to reach out to the workforce, including the trade union a number of initiatives were promoted. This included the introduction of a common uniform for workers and managers; a common canteen facility; common bus service for commuting between residence and manufacturing unit; communication events like Town Hall meetings attended by workers and managers together and 'family days', cultural events, sports, and other activities where blue and white collar workers were provided with a common platform for shared experiences. Workshops for trade union officials were arranged and independently led, in an effort to establish a new basis for consultation and negotiation. Outstanding grievances (for example, in relation to absence and time-keeping) were resolved and permanently removed from the agenda.

The organization introduced a performance management system (PMS) for the unionized staff — an unusual step in India. The PMS focuses not only on worker productivity but also measures their competency levels. A performance linked award recognizes and rewards high performers. The HR team conducted workshops to sensitize the workers on the importance of the PMS and to help gain their acceptance. Workers were involved as team members along with their managers - in improvement initiatives like Total Productivity Management, continuous improvement processes, and stretch projects in the manufacturing unit. This helped in building an atmosphere where employees at all levels came together as a team to bring 
continual improvements in the organization vying with each other and creating a competitive, yet constructive environment.

Specifically in relation to HRD, at the heart of our forward-looking thinking, was the line manager. We felt this role was key to a raft of changes that were necessary and which ultimately would impact in enhanced performance management and productivity improvements. Managers needed to take greater responsibility for managing their people; from recruitment through to exit. We looked closely at existing data produced by our ongoing surveys and listened carefully to the voice of both employees and managers. The workplace lacked a culture of praise and recognition for work well done. Involvement of the workforce was minimal. Little by way of ongoing onthe-job development was taking place. There was concern that appraisals were not always fair, open and honest.

For the management staff — the existing PMS was greatly improved to make it more fair, transparent, equitable, simple, and effective. A survey was conducted to understand the opinion and satisfaction of the management staff with the existing system. The outcome indicated a need to work on managers' style of providing feedback, simplifying the appraisal process, making performance ratings more equitable, and ongoing recognition of achievements of individuals and teams. The HR team organized training programmes for managers on setting goals, giving continuous feedback, and conducting appraisals. Moderation meetings, chaired by business heads and facilitated by HR business partners, were introduced in order to calibrate performance ratings - making the process fair and just. It was ensured that while rating the performance of individuals the comparison was done with the peers in the same cadre. This ensured that both high and low performance ratings were equally distributed across the hierarchy and relative ranking was adopted in the true sense.

With positive feedback emerging from the raft of initiatives noted above the basis was established for a specific HRD led initiative in respect of manager development. Much work had been done over a relatively short space of time to develop a new approach to working and managing at DFPCL. Whilst not always smooth sailing sufficient progress was made to generate an environment where the launch of a manager development programme could begin.

\section{Manager Development}

The key question we, as a small team of HRD professionals, were seeking to answer was how best to introduce and manage an initiative to develop our managers in such a way that they could, over time, take greater responsibility for the management and development of their teams. We needed:

a) To sensitize managers to accept that this was part of their jobs as managers and

b) To enable this to become part of their management practice.

We had the 'in principle' support of the CMD. We had a wealth of data from our feedback instruments and importantly we had our own sense of how things could be different. This was developed from our combined experiences which included work experience in other organizations and importantly our professional education (and its reference to the emerging evidence base as regards such $\mathrm{HR} / \mathrm{HRD}$ practices elsewhere in the world). With an improving industrial relations climate, the HRD team proposed and gained approval for its manager development initiative. 


\section{A guiding framework}

We took a low-key approach to begin with. Working with a pilot group of managers we ran a couple of reflective workshops. We wanted managers to take a mirror and look at themselves. Reflective exercises addressed "how were they managing?" "what was working what was not?" "what might make a difference?" We wanted to get them thinking about managing. We wanted to discuss leadership with them and what this meant to them and how different leadership styles might be considered. The positive feedback helped us formulate a set of broad 'learning' objectives which we felt were central and relevant, to a greater or lesser extent, to all our first line managers. These coalesced around management practice changes which would:

- Improve managers' commitment to take ownership of people practices and processes.

- Enhance communication between managers and employees.

- Providing more praise and recognition to employees.

- Develop coaching competencies in the managers.

- Develop managers as trainers and developers of their teams.

and which in terms of an initiative to progress was conceptualized within a framework we called Leading Our Teams (Figure 1).

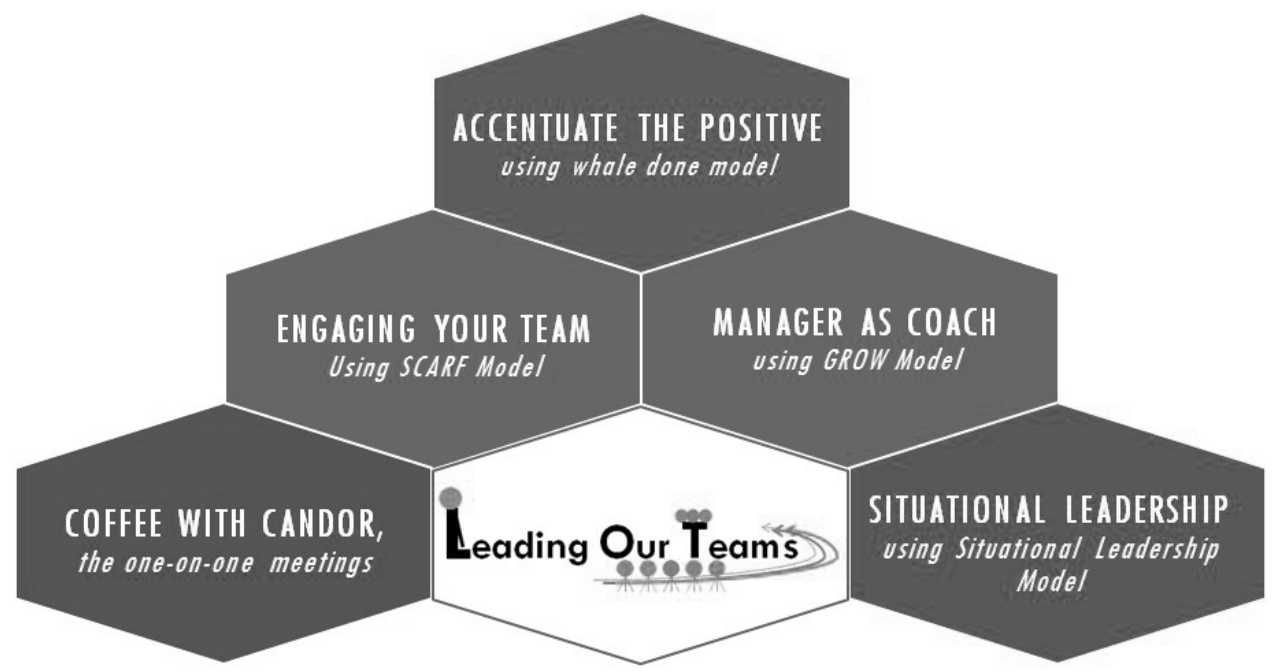

Figure 1: Leading Our Teams Framework

A series of interventions were designed to translate this framework into practice, focusing on providing tools and techniques to managers to identify and understand the people management challenges and adopt leadership styles that would help them improve team effectiveness. Overall, the programme is a mix of classroom training, practices for enhanced communication between managers and employees, and continuous inputs to the managers for ongoing development. The key components, are as follows:

- Facilitating Change Through Positive Reinforcement - a compact and interactive classroom session that introduces the managers to specific application of the Whale Done Model (Blanchard, 2003) for bringing behavioural change in individuals using positive reinforcements. 
- Flex Your Leadership Style — a video-based classroom session for introducing leaders to the concept of situational leadership and to introduce the idea of flexing their leadership style depending upon the situation and development level of their employees.

- Manager as Coach - a long-term (4 month) programme where managers are coached by an external coach to become coaches themselves. The GROW model (Whitmore, 2009; CIPD, 2012) underpins the approach adopted within this key component of the Leading Our Teams framework.

- Engaging your Employees - a half day interactive workshop where managers are introduced to the neuroscience based SCARF (Status, Certainty, Autonomy, Relatedness, and Fairness) model (Rock, 2008) — and which we use to help managers maximize the reward response and minimize the threat response while interacting with the employees — thereby improving employee engagement.

- Leadership Checklist - a checklist of behaviours was developed and shared with the managers to provide them with a guide to behaviours expected from them as managers. The list was developed based on the feedback received from employees.

- Coffee with Candor - an employee engagement initiative where managers practice weekly, structured, open, and dedicated interactions with their direct reports to strengthen working relationships, drive performance, and improve engagement. We developed manager toolkits and conducted workshops before the roll out of this intervention

- Weekly Leaders Feed for managers - through this initiative learning is reinforced through reworked messages like sharing articles, one point lessons, case studies, best HR practices, research findings etc. The Leaders Feeds, as infographics, runs on the display screens in common areas like canteens, waiting rooms etc.

\section{Individual development plans}

It is important to note a complementary initiative - that of the IDPs. Pushing more responsibility to employees, at all levels, to take ownership of the management of their own learning within DFPCL is another of our underpinning approaches to HRD in the business. Specifically, in relation to the manager development programme, the IDP provides a means of linking the various initiatives and drawing together the learning in relation to an individual's development. For managers, their IDP is framed against a set of leadership competencies e.g. leading self, leading others, leading business, leading change. It provides a tool to harness inputs from various sources, including 360-degree feedback and Hogan Profiling; a contemporary measure of personality in relation to job performance within specifically business and commercial environments (Hogan Assessments, Hogan Assessments; www.hoganassessments.com), thus ensuring no one source of information is given undue weight/influence.

\section{Developing the workforce ... beyond management}

It is useful to think of DFPCL's manager development programme as the first phase of a more ambitious plan to develop the workforce more generally. Such aspirations sit comfortably with the company's aim, as noted above, post 2014, to develop DFPCL as a better place to work, with more harmonious and less adversarial relations at the workplace. However, it was also a response to key economic and performance drivers. Firstly, the nature of our work is changing - greater 
use of complex technology etc. - with the result that jobs are changing, requiring expanded skills sets and an enhanced level of decision making in order to meet performance targets. Secondly, there is increasing need to strengthen the internal labour market within DFPCL; to develop employees to a level where they can provide a pool of new recruits to move into senior management roles. Whilst much of this first phase is now complete (although see below as regards the challenge of sustaining changed behaviours) our attention is now shifting to the goal of developing the workforce more broadly.

Our manager development programme has important elements within it which provide the basis for extending the role of managers into the trainers and developers of their teams. We have adopted the 70:20:10 model (Center for Creative Leadership, https://702010institute.com/) to help us progress this. In the model, 70 percent is experiential learning, $20 \%$ is learning from others (coaches, peers, networking, etc), and $10 \%$ is from formal means e.g. classroom, reading. We anticipate that as managers develop into coaches they will be able to provide coaching support to their team members. This support along with $10 \%$ conceptual inputs will be able to together underpin the $70 \%$ experiential learning through specific development projects and assignments.

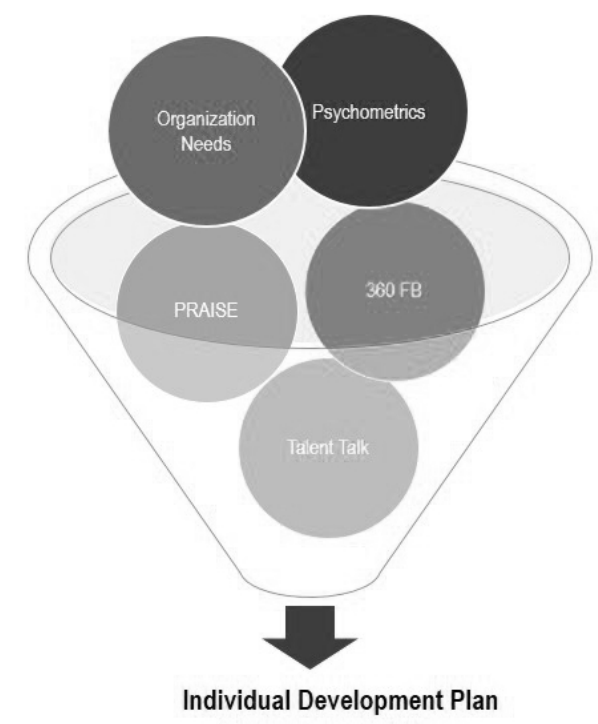

Figure 2: Inputs from Various Sources for Crafting IDP

\section{Impact}

Behavioural change is often a gradual process that takes time to fully take effect (see also our reflections on our practice below). However, we are also aware that we cannot ignore the need to assess impact both to justify the intervention and to provide ongoing feedback to enhance future interventions. Our main sources of data are qualitative feedback from participants (and their managers), survey data, focused group discussions with employees, and engagement in the IDP process. From such data, we conclude that the manager led development interventions have provided useful tools to managers for improved performance management of employees. We know from first-hand experience that managers are taking greater responsibility for people management; they are coaching their employees, they are integrally involved in talent 
management through the performance management system. The framework we have provided is achieving our goal of enabling managers to take on board these responsibilities. We illustrate in Figure 3 the outcomes of a recent survey. This captures feedback from employees and gives an indication as to perceptions on issues such as communication on business issues and priorities, feedback, and development goals.



Figure 3: Employee Feedback, December 2016 (DFPCL)

Ultimately, we must judge our success with the manager development programme in relation to a number of key performance indicators; for example, attrition, engagement, and productivity. These are beginning to show promising improvements. Company revenues have been increasing. Plant production has been consistently increasing while the number of non-management workers at the plant has come down. Employee attrition is dropping year on year. Employee engagement measures are heading upwards. Importantly also we note that the number of people being promoted internally, from the workforce, is beginning to be noticeable and significant, thus strengthening the internal labour market. This is vital as the company continues to grow and establish new manufacturing units. Whilst recognizing the difficulty inherent in attributing such 'benefits' to the implementation of the manager developing initiatives - relevance must also be attributed to the improvements in the broader climate of workplace relations — nonetheless our claim is for positive impact. The evidence available to us suggests the company is becoming better equipped to meet its targets of business growth and expansion. Our contribution has been to provide the opportunities for personal growth with DFPCL's people managers but targeted to a set of capabilities regarding leading and managing their teams. This same group of managers are key to HRD's aspirations to enabling such opportunities for growth and development to be inclusive rather than exclusive to one group.

\section{Reflecting on Our Practice}

From the outset we clearly faced a number of challenges, some of which are ongoing. We reflect here on four key themes - making the case; an integrative approach; managerial band-width; 
and our commitment to reflective practice itself - and which together address our practice as HRD professionals in relation to the challenges faced.

\section{Making the case}

We recognized that there could be no 'quick fix'; a range of interventions would be required over time. We were also acutely aware that levels of trust in HR generally were low. We had to seek engagement before we could look to change behaviours. We had to make our case and establish a degree of trust both with senior management and with those who would be participants on the programme. We had to challenge prevailing assumptions held by many that HR would continue to 'take care of people issues'. This demanded constant challenging and questioning in the daily and weekly dialogues of the workplace. On reflection, our case was helped by three factors:

- To assist 'buy in' for the manager development initiative it was important to give business heads a sense of ownership in the programme. We Involved them in both the design and communication about the interventions and sought to align the intervention with their perceived business needs.

- The steps we had taken immediately following the settlement with the union began to establish ourselves in a new light.

- These same 'early successes' were critical in gaining the support of the CMD; his support as a champion of a new approach to HR was vital in enabling us to progress on a range of strategic developments.

We note also the challenge of convincing some sceptical voices within HR itself and where there was some reluctant to relinquish their traditional power base in terms of managing people. However, the emerging evidence of impact from an initiative which has engaged virtually all our people managers has seen such doubts recede and dissipate.

\section{An integrative approach}

We feel the framework devised provided a fit for purpose — DFPCL 'stamp' — to our goals for manager development. It was no cut and paste exercise but nor did we try to re-invent the wheel. We adopted ideas from the literature surrounding good practice, proven tools in the world of HR and HRD, together with our own experience from work in other organizations and adapted them to suit the organization context and needs.

Considerable effort was placed in constructing a programme which provided an integrative approach. Component parts of the framework built on what had been done previously. Clearly managers moved through the Leading Our Teams programme at different paces and facing different issues and contexts as regards their teams. A way of ensuring the programme remained grounded in the practice of managing was the complementary tool of the IDP. This provided a vital link to the broader talent management and performance review processes within the organization. Again, the IDP sought to draw in practices which would ensure the IDP sat comfortably with the broad goals of the manager development programme and indeed the broader workplace development issues noted earlier.

Learn-Practice-Learn proved important as key design principle as regards the off-job classroom based training. Acutely conscious of potential transfer difficulties, we endeavoured to build in 
clear formats and devices to assist managers try out new behaviours, begin coaching members of their own teams and each formal workshop began with a 'shared' experience' session in order to provide a collective, reflective discussion designed to identify transfer problems and reinforce learning and amend and tune actions plans.

\section{Managerial band-width}

A major challenge - and one which is ongoing — related to what it is realistic for HRD to expect of programme participants. Managers in DFPCL increasingly have a broader remit and indeed our efforts to encourage them to take ownership of their team and people management is one of other increasing demands on their time. Coaching activity, for example, is not a quick fix. It takes time to prepare, deliver, and reflect on outcomes. Similarly, managing IDPs. We call the range of demands on a manager's time their 'band-width'. It is not elastic and we must recognize that. We have learnt to tread cautiously and sensitively as regards our demands on them as part of the programme.

Relatedly, we have had to recognize that behavioural change following an HRD intervention is not a given. It requires constant reinforcement and attention to transfer issues. Early stages of practice can be disappointing and problematic. The coaching session doesn't work out quite like it did when worked on in the workshop. Positive feedback from doing new and different things may take time to show. The need for support is most apparent in the early days of transfer and initial practice at new ways of doing things. Ultimately, we believe the problem of managerial band-width will be resolved by new behaviours and ways of working becoming accepted as the norm; simply 'part and parcel' of everyday performance as an effective manager. Critical here is the wider talent and performance management system that managers are part of and which provides assessment against key leadership objectives, the use of IDPs, together with intelligent use of our HRD analytics.

\section{Reflective practice}

We are champions of reflective practice. From the outset, our work with managers adopted an approach which sought to get managers to look inward and understand themselves better in terms of their capabilities and new challenges. This is something which is adopted in our own practice as HRD professionals. It requires us to avoid assumptions that 'we know best' and that we can effectively introduce a prescriptive based solution. Much of what we have done has involved us experimenting, taking feedback, and engaging in reflective dialogue amongst ourselves. It was important to question our own practice. For example, we revisited our dependence on a video based approach as regards our situational leadership workshops. We scrapped our first batch of videos; they were boring and ineffective. Whilst we remain of the view that video can be a powerful aid to the trainer it needs very careful thought about how best it can add value - any temptation to use it as an easy solution is likely to back-fire.

Our selection of participants for the early manager learning workshops proved problematic. A number of participants in early workshops were nearing retirement. Whilst not disruptive it was clear they were ambivalent to the broad goals and expectations of the programme. The level of engagement was such that it was difficult to run a session with a level of interaction to help generate positive learning outcomes. We subsequently did not leave selection to chance, but rather endeavoured to ensure that each workshop was attended by managers with a mix of 
experience, a range of experience with the business; different spans of control and include both those who were first-line managers of employees and managers' managers.

Our regular reflective 'huddles' are characterized by an openness, a freedom to disagree, to express ideas, and try and things out. If something doesn't seem to be working we ask why, including the assumptions we are making about our approach and the fitness for purpose of our plans and programmes. We accept that what we have achieved through the Leading Our Teams framework may be not be appropriate in four or five year's time and may need itself to evolve and change.

\section{Conclusions}

The business and industrial relations context of 2013-14 provided the opportunity for HRD to take a more strategic role within the organization. Over a period of 3 years we have established HRD as a function with stature and influence. We have succeeded in convincing the CMD and the Board of the contribution we can make. This has demanded conviction and commitment on our part. We ensured we understood the context into which our manager development initiative was to be introduced. Together with colleagues in HR we did much work to engage with the workforce prior to introducing change and which was also critical in establishing ourselves as credible in the eyes of top management. We have been able to lead an initiative rather than simply respond. Well established models have been drawn into our HRD practice - e.g. Whale Done, GROW etc. - and which have been harnessed to good effect within the implementation of the Leading Our Teams framework. Our resolve at the outset to invest in ongoing evaluation and feedback ensured we stayed 'in tune' with the voice of the manager; invaluable in maintaining trust and engagement. Ongoing HRD support to ensure effective transfer of learning into the workplace and to sustain behavioural change remains a priority. HRD at DFPCL has shifted from a traditional, prescriptive 'training' oriented function to more of an enabling function. We remain committed to our principles of reflective practice - both with those we work with and in terms of how we work as an HRD team. A continual process of questioning, rather than delivering easy solutions, is key to continuing to make a contribution in this vein.

\section{Editorial Reflection}

This article is an account of HRD practice within DFPCL, a large manufacturing company in India. Its focus is the role of the line manager (first or front-line managers, team leaders, supervisors etc.) in managing people within modern day organizations. This issue has seen extensive policy/ practice discussion and debate (see for example, Sisson \& Storey, 2000; Purcell, et al., 2003; Capelli, 2015; Wright, 2015; CIPD, 2016) over a period of 20+ years. However, until relatively recently research examining the link between HRD and organizational performance has rather ignored the part played by front-line managers in people management.

This is changing - at least as reflected within the western based research literature. The UK research assessment exercise ${ }^{2}$, for example, is increasingly concerned with identifying impact. Its 2014 assessment highlights research (and see for example, Hutchinson \& Purcell, 2007, 2008) which demonstrates that "front-line managers (such as team leaders) are critical to organizational effectiveness" and notes the role of such research in informing the implementation of HRD 
policy to support front-line managers more effectively in their role as people managers in diverse organizations. The research, it is claimed, has:

directly influenced the policies and learning materials of the Chartered Institute of Personnel and Development, as well as the advisory service ACAS and a variety of public policy documents that have informed organizations HR practice in supporting and developing front-line managers (REF, 2014).

The emergent evidence base, therefore, whilst still patchy, is nonetheless becoming influential in supporting practices to develop managers in people development.

However, outside of a predominantly western based discourse, the evidence base is largely non existent. Specifically, in the context of India, Azmi and Mustahtaq (2015) acknowledge the failure of research to address this issue arguing that as one of the world's:

most compelling markets, offering many business opportunities for Indian and multi-national companies, an investigation into the role of the line managers vis-à-vis HRM is likely to offer useful insights into the corporate terrain of India.

Their study develops an instrument to measure the strength of relationship between dimensions of line involvement in decision making as regards HRM and organizational effectiveness. Their findings offer broad support for a relationship of positive impact but importantly they note findings which they suggest may reflect the different context of HR dynamics which operate in India.

It is useful to conclude this account of practice with these reflective notes relating to the impact of HR/HRD upon the role of front-line managers in people management and development. The importance of this account is that it contributes to an emergent evidence base. And, importantly, it complements Azmi and Mustahtaq's work by providing a much needed case study of practice within a non-western context. Thus, the authors of this article contribute to our understanding of how HRD can lead a shift in line management role and responsibility and through this impact organizational development and effectiveness. It will hopefully stimulate further practice-based enquiry into the relationship between HRD and line management and in contexts where we need to be sensitive to cross cultural differences.

\section{Notes}

1 The article is based on, and developed from, a submission to the International Federation of Training and Development Organisation's Annual Global Awards. The company were successful in winning the IFTDO Award for Best HRD Practice, 2017.

2 The UK regularly assesses the quality of research in its higher education institutions. The exercise addresses all disciplines. HR and HRD are part of the assessment of business and management research.

\section{References}

Azmi, F. T., \& Mustahtaq, S. (2015). Role of line managers in human resource management: empirical evidence from India, The International Journal of Human Resource Management, 26(5), 616-639.

Blanchard, K. (2003). Whale Done: The power of positive relationships, New York, The Free Press.

Capelli, P. (2015). Why We Love to Hate HR ... and What HR Can Do About It, Harvard Business Review, July-August. 
CIPD (2012). Coaching: the evidence base, Research Report, Chartered Institute of Personnel and Development.

CIPD (2016). The role of line managers in HR and L\&D; Factsheet, London, Chartered Institute of Personnel and Development. Retrieved from https://www.cipd.co.uk/knowledge/fundamentals/people/ $\mathrm{hr}$ /line-managers-factsheet

Hutchinson, S., \& Purcell, J. (2007). The role of line managers in reward, and training, learning and development, Research Report, CIPD. Retrieved from http://www.cipd.co.uk/Bookstore/_catalogue/ CorporateAndHRStrategy/9781843981954.htm

Hutchinson, S., \& Purcell, J. (2008). Front-line managers and the effective delivery of people management in the NHS, Department of Health. Retrieved from http://www1.uwe.ac.uk/bl/bbs/bbsresearch/cesr/ cesrreports.aspx

Purcell, J., Kinnie, N., Hutchinson, S., Rayton, B., \& Swart, J. (2003). Understanding the People and Performance Link: Unlocking the Black Box. London: Chartered Institute of Personnel and Development.

REF (2014). Recognising and supporting front-line managers in delivering effective people management, Impact Case study. Retrieved from http://impact.ref.ac.uk/CaseStudies/CaseStudy.aspx?Id=39832

Rock, D. (2008). SCARF: a brain-based model for collaborating with and influencing others, Neuroleadership Journal, 1(1).

Sisson, K., \& Storey, J. (2000). The realities of human resource management: managing the employment relationship, Open University Press.

Whitmore, J. (2009). Coaching for Performance, London: Nicholas Brealey Publishing.

Wright, H. (2015). Line manager roles are key to a great workplace, Personnel Today, 20 May, 2015.

\section{The Authors}

Naresh Pinisetti is a Post Graduate in HR from NIPM with an Executive MBA from Scandinavian International Management Institute (SIMI). He has also done his BL and MA(Sociology) from Andhra University. Naresh is currently associated with Deepak Fertilisers and Petrochemicals Corporation Ltd as Group President - HR. Previously, he was associated with Vestas, Bayer, and Nagarjuna Fertilizers, in senior leadership roles. He has over 30 years' experience in HRD and Industrial Relations. He is a certified Coach and a Hogan Graduate. Naresh was awarded as one of 100 Most Talented Global HR Leaders by the World HR Congress in 2014.

Ashutosh Sharma has done the Post Graduate Program in General Management from the University of California, Los Angles and B.E. in Electrical Engineering from the University of Delhi. He has 15 years experience in the field of Talent Management and Leadership Development. He is currently associated with Deepak Fertilisers and Petrochemicals Corporation Ltd as General Manager - Corporate HR. Previously, he has worked with GMR Group, Confederation of Indian Industry and SRF Ltd. Ashutosh has authored two books: Campus to Corporate-Managing the Transition and Corporate Training FactPack.

Preeti Datta is a Masters in Personnel Management from University of Pune with six years of experience in the field of HRD. She specializes in Training, Talent Management, and Leadership Development. She is currently associated with Deepak Fertilisers and Petrochemicals Corporation Ltd as a Senior Manager - Corporate Human Resources. 